\title{
Research Article \\ Fixed Point Theorems by Ways of Ultra-Asymptotic Centers
}

\author{
S. Dhompongsa ${ }^{1,2}$ and N. Nanan ${ }^{1}$ \\ ${ }^{1}$ Department of Mathematics, Faculty of Science, Chiang Mai University, Chiang Mai 50200, Thailand \\ ${ }^{2}$ Materials Science Research Center, Faculty of Science, Chiang Mai University, Chiang Mai 50200, \\ Thailand \\ Correspondence should be addressed to S. Dhompongsa, sompongd@chiangmai.ac.th
}

Received 24 December 2010; Revised 23 April 2011; Accepted 23 May 2011

Academic Editor: Allan C. Peterson

Copyright (C) 2011 S. Dhompongsa and N. Nanan. This is an open access article distributed under the Creative Commons Attribution License, which permits unrestricted use, distribution, and reproduction in any medium, provided the original work is properly cited.

We use an approach on ultra-asymptotic centers to obtain fixed point theorems for two classes of nonself multivalued mappings. The results extend and improve several known ones.

\section{Introduction}

Domínguez Benavides and Lorenzo Ramírez [1-3] introduced a new method to prove the existence of fixed points using asymptotic centers as main tools by comparing their asymptotic radii with various geometric moduli of Banach spaces. The method led Dhompongsa et al. [4] to define the (DL) condition and obtained a fixed point theorem by following the proof in [1].

Definition 1.1 (see [4, Definition 3.1]). A Banach space $X$ is said to satisfy the DomínguezLorenzo condition ((DL) condition, in short), if there exists $\lambda \in[0,1)$ such that for every weakly compact convex subset $E$ of $X$ and for every bounded sequence $\left\{x_{n}\right\}$ in $E$ which is regular relative to $E$,

$$
r_{E}\left(A\left(E,\left\{x_{n}\right\}\right)\right) \leq \lambda r\left(E,\left\{x_{n}\right\}\right)
$$

Theorem 1.2 (see [4, Theorem 3.3]). Let $X$ be a reflexive Banach space satisfying the (DL) condition, and let $E$ be a bounded closed and convex separable subset of X. If $T: E \rightarrow K C(X)$ is 
a nonexpansive and $1-x$-contractive mapping such that $T(E)$ is a bounded set and which satisfies the inwardness condition: $T x \subset I_{E}(x)$ for all $x \in E$, then $T$ has a fixed point.

Wiśnicki and Wośko [5] introduced an ultrafilter coefficient $\mathrm{DL}_{\mathfrak{U}}(X)$ for a Banach space $X$ and presented a fixed point result under a stronger condition than the (DL) condition.

Definition 1.3 (see [5, Definition 5.2]). Let $\mathcal{U}$ be a free ultrafilter defined on the set of natural numbers $\mathbb{N}$. The coefficient DL $\mathcal{U}(X)$ of a Banach space $X$ is defined as

$$
\operatorname{DL}_{\mathcal{U}}(X)=\sup \left\{\frac{\chi_{E}\left(A_{\mathcal{U}}\left(E,\left\{x_{n}\right\}\right)\right)}{\chi_{E}\left(\left\{x_{n}\right\}\right)}\right\}
$$

where the supremum is taken over all nonempty weakly compact convex subsets $E$ of $X$ and all weakly, not norm-convergent sequences $\left\{x_{n}\right\}$ in $E$ which are regular relative to $E$.

Theorem 1.4 (see [5, Theorem 5.3]). Let E be a nonempty weakly compact convex subset of a Banach space $X$ with $D L_{\mathfrak{U}}(X)<1$. Assume that $T: E \rightarrow K C(X)$ is a nonexpansive and $1-X^{-}$ contractive mapping such that $T x \subset I_{E}(x)$ for all $x \in E$. Then $T$ has a fixed point.

Observe that, unlike Theorem 1.2, it does not assume the "separability" condition on $E$ in Theorem 1.4. However, it should be mentioned that the idea of the proof came from the original one of Domínguez Benavides and Lorenzo Ramírez [1]. At the same time, with the same purpose, Garvira [6] introduced independently its counter part in terms of ultranets.

Definition 1.5 (see [6, Definition 3.1.2]). A Banach space $X$ is said to have the (DL) condition with respect to a topology $\tau\left(\tau(\mathrm{DL})_{\alpha}\right.$ condition) if there exists $\lambda \in[0,1)$ such that for every $\tau$-compact convex subset $E$ of $X$ and for every bounded ultranet $\left\{x_{\alpha}\right\}$ in $E$

$$
r_{E}\left(A\left(E,\left\{x_{\alpha}\right\}\right)\right) \leq \lambda r\left(E,\left\{x_{\alpha}\right\}\right) .
$$

When $\tau$ is the weak topology $\omega$ we write (DL) ${ }_{\alpha}$ condition instead of $\omega(\mathrm{DL})_{\alpha}$ condition.

It follows from [6, Proposition 3.1.1] that the (DL) ${ }_{\alpha}$ condition is stronger than the (DL) condition. The ultranet counterpart of Theorem 1.4 becomes:

Theorem 1.6 (special case of [6, Theorem 3.5.2]). Let X be a Banach space satisfying the $(D L)_{\alpha}$ condition. Let $E$ be a weakly compact convex subset of $X$. If $T: E \rightarrow K C(X)$ is a nonexpansive and $1-x$-contractive mapping such that $T x \subset I_{E}(x)$ for $x \in E$, then $T$ has a fixed point.

In 2006, Dhompongsa et al. [7] introduced a property for a Banach space X.

Definition 1.7 (see [7, Definition 3.1]). A Banach space $X$ is said to have property $(D)$ if there exists $\lambda \in[0,1)$ such that for any nonempty weakly compact convex subset $E$ of $X$, any sequence $\left\{x_{n}\right\} \subset E$ which is regular and asymptotically uniform relative to $E$, and any sequence $\left\{y_{n}\right\} \subset A\left(E,\left\{x_{n}\right\}\right)$ which is regular and asymptotically uniform relative to $E$ one has

$$
r\left(E,\left\{y_{n}\right\}\right) \leq \operatorname{\lambda r}\left(E,\left\{x_{n}\right\}\right) .
$$


Theorem 1.8 (see [7, Theorem 3.6]). Let E be a nonempty weakly compact convex subset of a Banach space $X$ which has property $(D)$. Assume that $T: E \rightarrow K C(E)$ is a nonexpansive mapping. Then $T$ has a fixed point.

The following definition is due to Butsan et al. [8].

Definition 1.9 (see [8, Definition 3.1]). Let $T: E \rightarrow E$ be a mapping on a subset $E$ of a Banach space $X$. Then $T$ is said to satisfy condition $(*)$ if

(1) for each T-invariant subset $K$ of $E, T$ has an afps in $K$,

(2) for each pair of $T$-invariant subsets $K$ and $W$ of $E, A\left(W,\left\{x_{n}\right\}\right)$ is $T$-invariant for each afps $\left\{x_{n}\right\}$ in $K$.

The main fixed point theorem concerning condition $(*)$ in [8] is Theorem 3.5 of which the correct statement should be stated as follows.

Theorem 1.10 (see [8, Theorem 3.5]). Let X be a Banach space having property $(D)$, and let $E$ be a weakly compact convex subset of $X$. Let $T: E \rightarrow E$ satisfy conditon $(*)$. If $T$ is continuous, then $T$ has a fixed point.

In fact, we can replace "continuity" by a weaker condition, namely " $I-T$ is strongly demiclosed at 0 ": for every sequence $\left\{x_{n}\right\}$ in $E$ strongly converges to $z \in E$ and such that $x_{n}-T x_{n} \rightarrow 0$ we have $z=T z$ (cf. [9]).

Following the concept of $D L_{\mathfrak{U}}(X)$, Dhompongsa and Inthakon [10] introduced the following coefficient.

Definition 1.11 (see [10, Definition 3.2]). Let $\boldsymbol{U}$ be a free ultrafilter defined on $\mathbb{N}$. The coefficient $D_{\mathfrak{U}}(X)$ of a Banach space $X$ is defined as

$$
D_{\mathcal{U}}(X)=\sup \left\{\frac{\chi_{E}\left(\left\{y_{n}\right\}\right)}{\chi_{E}\left(\left\{x_{n}\right\}\right)}\right\},
$$

where the supremum is taken over all nonempty weakly compact convex subsets $E$ of $X$, all sequences $\left\{x_{n}\right\}$ in $E$ which are weakly, not norm-convergent and are regular relative to $E$ and all weakly, not norm-convergent sequences $\left\{y_{n}\right\} \subset A_{\mathfrak{U}}\left(E,\left\{x_{n}\right\}\right)$ which are regular relative to E.

A concept corresponding to the coefficient $D_{\mathfrak{U}}(X)$ is the following property.

Definition 1.12 (see [10, Definition 3.1]). A Banach space $X$ is said to have property $\left(D^{\prime}\right)$ if there exists $\lambda \in[0,1)$ such that for any nonempty weakly compact convex subset $E$ of $X$, any sequence $\left\{x_{n}\right\} \subset E$ which is regular relative to $E$, and any sequence $\left\{y_{n}\right\} \subset A\left(E,\left\{x_{n}\right\}\right)$ which is regular relative to $E$ one has

$$
r\left(E,\left\{y_{n}\right\}\right) \leq \lambda r\left(E,\left\{x_{n}\right\}\right)
$$

Obviously, $\mathrm{DL} \mathcal{u}(X)<1 \Rightarrow(\mathrm{DL}) \Rightarrow\left(D^{\prime}\right) \Rightarrow(D)$. Several well-known spaces have been proved to satisfy the (DL) condition and to have property $\left(D^{\prime}\right)$ (see, e.g., $[1,4,7,11-16]$ ). 
The class of spaces having property $\left(D^{\prime}\right)$ includes both spaces satisfying the (DL) condition as well as spaces satisfying the Kirk-Massa condition (see Section 3.2 for the definition of the condition). One of the main results in [10] is the following theorem.

Theorem 1.13 (see [10, Theorem 1.9]). Let E be a nonempty weakly compact convex subset of a Banach space $X$, and let $X$ have property $\left(D^{\prime}\right)$. Assume that $T: E \rightarrow K C(X)$ is a nonexpansive and $1-x$-contractive mapping such that $T x \subset I_{E}(x)$ for every $x \in E$. Then $T$ has a fixed point.

Due to Kuczumow and Prus [17], we can assume without loss of generality that $E$ in Theorem 1.8 is separable. Theorem 1.13 does not only extend Theorem 1.8 to nonselfmappings, but it can remove "separability" condition on the domains of the mappings in Theorem 1.2 without refering to ultrafilters or ultranets in its statement. The key to the proof of Theorem 1.13 is the following.

Theorem 1.14 (see [10, Theorem 3.4]). Let E be a weakly compact convex subset of a Banach space $X$ and $\mathcal{U}$ a free ultrafilter defined on $\mathbb{N}$. Then $D_{\mathcal{U}}(X)<1$ if and only if $X$ has property $\left(D^{\prime}\right)$.

Thus, unlike the coefficient $\operatorname{DL}_{\mathfrak{U}}(X)$, we have, for any two free ultrafilters $\mathcal{U}$ and $\mathcal{U}$, $D_{\mathcal{U}}(X)<1$ if and only if $D_{\mathcal{U}}(X)<1$.

In Section 3.1, we extend Theorem 1.10 to multivalued nonself-mappings for spaces having property $\left(D^{\prime}\right)$. Examples of such mappings are given. To obtain a fixed point result for more mappings, a new class of mappings is introduced in Section 3.2. Some examples of those mappings are also given. Our results extend and improve several known results in [8-10, 18-25] and many others (see Remark 3.4).

\section{Preliminaries}

Let $E$ be a nonempty closed and convex subset of a Banach space $X$. We will denote by $2^{X}$ the family of all subsets of $X, C B(X)$ the family of all nonempty bounded and closed subsets of $X$ and denote by $K C(X)$ the family of all nonempty compact convex subsets of $X$. For a given mapping $T: E \rightarrow C B(X)$ the set of all fixed points of $T$ will be denoted by $F(T)$, that is, $F(T):=\{x \in E: x \in T x\}$. Let $H(\cdot, \cdot)$ be the Hausdorff distance defined on $C B(X)$, that is,

$$
H(A, B):=\max \left\{\sup _{a \in A} \operatorname{dist}(a, B), \sup _{b \in B} \operatorname{dist}(b, A)\right\}, \quad A, B \in C B(X)
$$

where $\operatorname{dist}(a, B):=\inf \{\|a-b\|: b \in B\}$ is the distance from a point $a$ to a subset $B$. A multivalued mapping $T: E \rightarrow C B(X)$ is said to be nonexpansive if

$$
H(T x, T y) \leq\|x-y\|, \quad \forall x, y \in E,
$$

and $T$ is said to be a contraction if there exists a constant $k<1$ such that

$$
H(T x, T y) \leq k\|x-y\|, \quad \forall x, y \in E
$$


A multivalued mapping $T: E \rightarrow 2^{X}$ is called $\phi$-condensing (resp., $1-\phi$-contractive), where $\phi$ is a measure of noncompactness, if for each bounded subset $B$ of $E$ with $\phi(B)>0$, there holds the inequality

$$
\phi(T(B))<\phi(B) \quad(\operatorname{resp} . \phi(T(B)) \leq \phi(B))
$$

where $T(B)=\bigcup_{x \in B} T x$.

Recall that the inward set of $E$ at $x \in E$ is defined by

$$
I_{E}(x)=\{x+\alpha(y-x): \alpha \geq 1, y \in E\}
$$

A sequence $\left\{x_{n}\right\}$ in $E$ for which $\lim _{n \rightarrow \infty}\left\|x_{n}-T x_{n}\right\|=0$ for a mapping $T: E \rightarrow E$ is called an approximate fixed point sequence (afps for short) for $T$. Analogously for a multivalued mapping $T: E \rightarrow C B(X)$, a sequence $\left\{x_{n}\right\}$ in $E$ of a Banach space $X$ for which $\lim _{n \rightarrow \infty} \operatorname{dist}\left(x_{n}, T x_{n}\right)=0$ is called an approximate fixed point sequence (afps for short) for $T$.

We denote by $x_{n} \rightarrow x$ to indicate that the sequence $\left\{x_{n}\right\}$ in $X$ converges to $x \in X$.

Let $E$ be a nonempty closed and convex subset of a Banach space $X$ and $\left\{x_{n}\right\}$ a bounded sequence in $X$. For $x \in X$, define the asymptotic radius of $\left\{x_{n}\right\}$ at $x$ as the number

$$
r\left(x,\left\{x_{n}\right\}\right)=\limsup _{n \rightarrow \infty}\left\|x_{n}-x\right\|
$$

Let

$$
\begin{gathered}
r\left(E,\left\{x_{n}\right\}\right):=\inf \left\{r\left(x,\left\{x_{n}\right\}\right): x \in E\right\}, \\
A\left(E,\left\{x_{n}\right\}\right):=\left\{x \in E: r\left(x,\left\{x_{n}\right\}\right)=r\left(E,\left\{x_{n}\right\}\right)\right\} .
\end{gathered}
$$

The number $r\left(E,\left\{x_{n}\right\}\right)$ and the set $A\left(E,\left\{x_{n}\right\}\right)$ are, respectively, called the asymptotic radius and asymptotic center of $\left\{x_{n}\right\}$ relative to $E$. The sequence $\left\{x_{n}\right\}$ is called regular relative to $E$ if $r\left(E,\left\{x_{n}\right\}\right)=r\left(E,\left\{x_{n^{\prime}}\right\}\right)$ for each subsequence $\left\{x_{n^{\prime}}\right\}$ of $\left\{x_{n}\right\}$. It was noted in [26] that if $E$ is nonempty and weakly compact, then $A\left(E,\left\{x_{n}\right\}\right)$ is nonempty and weakly compact, and if $E$ is convex, then $A\left(E,\left\{x_{n}\right\}\right)$ is convex.

Proposition 2.1 (see [27, Theorem 1]). Let $\left\{x_{n}\right\}$ and E be as above. Then there exists a subsequence of $\left\{x_{n}\right\}$ which is regular relative to $E$.

We now present the formulation of an ultrapower of Banach spaces. Let $\boldsymbol{U}$ be a free ultrafilter on $\mathbb{N}$. Recall $([26,28-30])$ that the ultrapower $(X)_{\mathcal{U}}$ of a Banach space $X$ is the quotient space of

$$
l_{\infty}(X)=\left\{\left\{x_{n}\right\}: x_{n} \in X \forall n \in \mathbb{N},\left\|\left\{x_{n}\right\}\right\|=\sup _{n}\left\|x_{n}\right\|<\infty\right\}
$$

by

$$
\operatorname{ker} \mathcal{N}=\left\{\left\{x_{n}\right\} \in l_{\infty}(X): \lim _{n \rightarrow \mathcal{U}}\left\|x_{n}\right\|=0\right\}
$$


One can proof that $\tilde{X}=(X)_{\mathcal{U}}$ is a Banach space with the quotient norm given by $\left\|\left\{x_{n}\right\}_{\mathcal{U}}\right\|=$ $\lim _{n \rightarrow \mathcal{U}}\left\|x_{n}\right\|$, where $\left\{x_{n}\right\}_{\mathfrak{U}}$ is the equivalence class of $\left\{x_{n}\right\}$. It is also clear that $X$ is isometric to a subspace of $\tilde{X}$ by the canonical embedding $x \mapsto\{x, x, \ldots\}_{\mathfrak{u}}$. If $E \subset X$, we will use the symbols $\dot{E}$ and $\dot{x}$ to denote the image of $E$ and $x$ in $\tilde{X}$ under this isometry, respectively, and denote

$$
\tilde{E}=\left\{\tilde{x} \in \tilde{X}: \exists\left\{x_{n}\right\} \text { such that } \tilde{x}=\left\{x_{n}\right\}_{u}, x_{n} \in E \forall n \in \mathbb{N}\right\}
$$

Thus $\dot{x}=\{x, x, \ldots\}_{\mathcal{U}}$ and $\dot{E}=\{\dot{x} \in \tilde{X}: x \in E\}$.

If $T: E \rightarrow C B(X)$ is a multivalued mapping, we define a corresponding multivalued mapping $\tilde{T}: \widetilde{E} \rightarrow \mathrm{CB}(\tilde{X})$ by

$$
\tilde{T}(\tilde{x}):=\left\{\tilde{u} \in \tilde{X}: \exists\left\{u_{n}\right\} \text { such that } \tilde{u}=\left\{u_{n}\right\}_{\mathfrak{u}}, u_{n} \in T x_{n} \forall n \in \mathbb{N}\right\} \text {, }
$$

where $\tilde{x}=\left\{x_{n}\right\}_{\mathcal{U}} \in \tilde{E}$. Moreover the set $\tilde{T}(\tilde{x})$ is bounded and closed (see [28, 29]). The Hausdorff metric on $C B(\tilde{X})$ will be denoted by $\widetilde{H}$.

Proposition 2.2 (see [5, Proposition 3.1]). For every $\left\{x_{n}\right\}_{\mathcal{u}}$ and $\left\{y_{n}\right\}_{\mathcal{U}}$ in $\widetilde{E}$,

$$
\widetilde{H}\left(\widetilde{T}\left\{x_{n}\right\}_{\mathcal{U}}, \widetilde{T}\left\{y_{n}\right\}_{\mathfrak{U}}\right)=\lim _{n \rightarrow \mathcal{U}} H\left(T x_{n}, T y_{n}\right)
$$

Proposition 2.3 (see [31, Page 37], [5, Proposition 3.2]). Let E be a nonempty subset of a Banach space $X$ and $T: E \rightarrow C B(X)$.

(i) If $T$ is convex-valued, then $\tilde{T}$ is convex-valued.

(ii) If $T$ is compact-valued, then $\tilde{T}$ is compact-valued and $\tilde{T} \dot{x}=(\dot{T} x)$ for every $x \in E$.

(iii) If $T$ is nonexpansive, then $\tilde{T}$ is nonexpansive.

Let $\mathcal{U}$ denote a free ultrafilter defined on $\mathbb{N}$. Wiśnicki and Wośko [5] defined the ultraasymptotic radius $r_{\mathfrak{U}}\left(E,\left\{x_{n}\right\}\right)$ and the ultra-asymptotic center $A_{\mathfrak{U}}\left(E,\left\{x_{n}\right\}\right)$ of $\left\{x_{n}\right\}$ relative to E by

$$
\begin{gathered}
r_{\mathcal{U}}\left(E,\left\{x_{n}\right\}\right)=\inf \left\{\lim _{n \rightarrow \mathcal{U}}\left\|x_{n}-x\right\|: x \in E\right\}, \\
A_{\mathcal{U}}\left(E,\left\{x_{n}\right\}\right)=\left\{x \in E: \lim _{n \rightarrow \mathcal{U}}\left\|x_{n}-x\right\|=r_{\mathcal{U}}\left(E,\left\{x_{n}\right\}\right)\right\} .
\end{gathered}
$$

It is not difficult to see that $A_{\mathfrak{U}}\left(E,\left\{x_{n}\right\}\right)$ is a nonempty weakly compact convex set if $E$ is. Notice that the above notions have a natural interpretation in the ultrapower $\tilde{X}$ [5]:

$$
r_{\mathcal{U}}\left(E,\left\{x_{n}\right\}\right)=\inf _{x \in E}\left\|\left\{x_{n}\right\}_{\mathcal{U}}-\dot{x}\right\|
$$


is the relative Chebyshev radius of $\left\{x_{n}\right\}_{\mathfrak{u}}$, and

$$
\left(A_{\mathfrak{U}}\left(\dot{E},\left\{x_{n}\right\}\right)\right)=\dot{E} \cap B_{\tilde{X}}\left(\left\{x_{n}\right\}_{\mathcal{U}}, r\right)
$$

is the relative Chebyshev center of $\left\{x_{n}\right\}_{\mathfrak{U}}$ relative to $\dot{E}$ in the ultrapower $\tilde{X}$. (Here $B_{\tilde{X}}\left(\left\{x_{n}\right\}_{\mathcal{U}}, r\right)$ denotes the ball in $\tilde{X}$ centered at $\left\{x_{n}\right\}_{\mathcal{U}}$ and of radius $r=r_{\mathcal{U}}\left(E,\left\{x_{n}\right\}\right)$.) It should be noted that, in general, $A\left(E,\left\{x_{n}\right\}\right)$ and $A_{\mathfrak{U}}\left(E,\left\{x_{n}\right\}\right)$ may be different. The notion of the asymptotic radius is closely related to the notion of the relative Hausdorff measure of noncompactness defined by Domínguez Benavides and Lorenzo Ramírez [1] as

$$
\chi_{E}(A)=\inf \{\varepsilon>0: A \text { can be covered by finitely many balls in } E \text { of radii } \leq \varepsilon\} .
$$

Proposition 2.4 (see [5, Proposition 4.5]). If $\left\{x_{n}\right\}$ is a bounded sequence which is regular relative to $E$, then

$$
r\left(E,\left\{x_{n}\right\}\right)=r_{\mathcal{U}}\left(E,\left\{x_{n}\right\}\right)=\chi_{E}\left(\left\{x_{n}\right\}\right) .
$$

From Proposition 2.4, we have, for $w \in A\left(E,\left\{x_{n}\right\}\right)$,

$$
\lim _{n \rightarrow \mathcal{U}}\left\|x_{n}-w\right\| \leq \limsup _{n \rightarrow \infty}\left\|x_{n}-w\right\|=r\left(E,\left\{x_{n}\right\}\right)=r_{\mathcal{U}}\left(E,\left\{x_{n}\right\}\right) .
$$

Therefore, $A\left(E,\left\{x_{n}\right\}\right) \subset A_{\mathfrak{U}}\left(E,\left\{x_{n}\right\}\right)$.

The following result plays an important role in our proofs.

Lemma 2.5 (see [10, Lemma 3.3]). Let $E$ be a nonempty closed and convex subset of a Banach space $X$ and $\left\{x_{n}\right\}$ a bounded sequence in $X$ which is regular relative to $E$. For each $\left\{y_{n}\right\} \subset A_{\mathcal{U}}\left(E,\left\{x_{n}\right\}\right)$, there exists a subsequence $\left\{x_{n^{\prime}}\right\}$ of $\left\{x_{n}\right\}$ such that $\left\{y_{n}\right\} \subset A\left(E,\left\{x_{n^{\prime}}\right\}\right)$.

A direct consequence of Lemma 2.5 is as follows. If every center $A\left(E,\left\{x_{n}\right\}\right)$ is compact for every bounded sequence $\left\{x_{n}\right\}$ in $E$ which is regular relative to $E$, then $A_{\mathfrak{U}}\left(E,\left\{x_{n}\right\}\right)$ is also compact for every bounded sequence $\left\{x_{n}\right\}$ in $E$ which is regular relative to $E$.

\section{Main Results}

\subsection{Property $\left(D^{\prime}\right)$}

Lemma 3.1. Let $E$ be a nonempty subset of a Banach space $X$ and $T: E \rightarrow C B(X)$. Then

(1) if $T$ is uniformly continuous, then $\tilde{T}$ is uniformly continuous;

(2) if $T$ is continuous at $z \in E$, then $\tilde{T}$ is continuous at $\dot{z}$.

Proof. (1) Let $\varepsilon>0$. Since $T$ is uniformly continuous, there exists $\delta>0$ such that $H(T x, T y)<$ $\varepsilon$ for each $x, y \in E$ with $\|x-y\|<\delta$. Suppose $\left\{x_{n}\right\}_{\mathcal{U}},\left\{y_{n}\right\}_{\mathcal{U}} \in \widetilde{E}$, and $\left\|\left\{x_{n}\right\}_{\mathcal{U}}-\left\{y_{n}\right\}_{\mathcal{U}}\right\|<\delta$. Let $A=\left\{n:\left\|x_{n}-y_{n}\right\|<\delta\right\}$ and $B=\left\{n: H\left(T x_{n}, T y_{n}\right)<\varepsilon\right\}$. Since $A \in \mathcal{U}$ and $A \subset B, B \in \mathcal{U}$. Thus, by Proposition $2.2 \widetilde{H}\left(\widetilde{T}\left\{x_{n}\right\}_{\mathcal{U}}, \widetilde{T}\left\{y_{n}\right\}_{\mathfrak{U}}\right) \leq \varepsilon$. 
(2) Let $\varepsilon>0$. Since $T$ is continuous at $z$, there exists $\delta>0$ such that $H(T x, T z)<\varepsilon$ for each $x \in E$ with $\|x-z\|<\delta$. If $\left\{x_{n}\right\}_{\mathfrak{U}} \in \widetilde{E}$ such that $\left\|\left\{x_{n}\right\}_{\mathcal{U}}-\dot{z}\right\|<\delta$, then, letting $A=\left\{n:\left\|x_{n}-z\right\|<\delta\right\}$ and $B=\left\{n: H\left(T x_{n}, T z\right)<\varepsilon\right\}$, we see that $A \in \mathcal{U}$ and $B \in \mathcal{U}$. Thus, by Proposition $2.2 \widetilde{H}\left(\widetilde{T}\left\{x_{n}\right\}_{\mathcal{u}}, \widetilde{T} \dot{z}\right) \leq \varepsilon$.

We now introduce condition $(*)$ for multivalued mappings.

Definition 3.2. Let $E$ be a nonempty subset of a Banach space $X$. A mapping $T: E \rightarrow C B(X)$ is said to satisfy condition $(*)$ if

(1) $T$ has an afps in $E$,

(2) $T$ has an afps in $A\left(E,\left\{x_{n^{\prime}}\right\}\right)$ for some subsequence $\left\{x_{n^{\prime}}\right\}$ of any given afps $\left\{x_{n}\right\}$ for $T$ in $E$.

Theorem 3.3. Let $X$ be a Banach space having property $\left(D^{\prime}\right)$, and let $E$ be a weakly compact convex subset of $X$. Assume that $T: E \rightarrow K C(X)$ is a multivalued mapping satisfying condition (*). If $T$ is continuous, then $T$ has a fixed point.

Proof. The proof follows by adapting the proof of [10, Theorem 1.9]. By (1) of Definition 3.2, let $\left\{x_{n}^{0}\right\}$ be an afps for $T$ in $E$. We can assume by Proposition 2.1 that $\left\{x_{n}^{0}\right\}$ is regular relative to $E$. Condition (2) of Definition 3.2 gives us a subsequence $\left\{x_{n_{0}}^{0}\right\}$ of $\left\{x_{n}^{0}\right\}$ so that the center $A\left(E,\left\{x_{n_{0}}^{0}\right\}\right)$ contains an afps for $T$. Denote $A^{0}=A\left(E,\left\{x_{n_{0}}^{0}\right\}\right)$, and let $\left\{x_{n}^{1}\right\}$ be an afps in $A^{0}$. Assume that $\left\{x_{n}^{1}\right\}$ is regular relative to $E$. As before, $T$ has an afps in $A\left(E,\left\{x_{n_{1}}^{1}\right\}\right)$ for some subsequence $\left\{x_{n_{1}}^{1}\right\}$ of $\left\{x_{n}^{1}\right\}$. Since $X$ has property $\left(D^{\prime}\right)$, put $\lambda=D_{\mathcal{U}}(X)<1$. Then, by Proposition 2.4 and Definition 1.11,

$$
r\left(E,\left\{x_{n_{1}}^{1}\right\}\right)=\chi_{E}\left(\left\{x_{n_{1}}^{1}\right\}\right) \leq \lambda_{X E}\left(\left\{x_{n_{0}}^{0}\right\}\right)=\lambda r\left(E,\left\{x_{n_{0}}^{0}\right\}\right)
$$

Continue the procedure to obtain, for each $m \geq 0$, a regular sequence $\left\{x_{n_{m}}^{m}\right\}$ relative to $E$ in $A^{m-1}:=A\left(E,\left\{x_{n_{m-1}}^{m-1}\right\}\right)$ such that

$$
\lim _{n \rightarrow \infty} \operatorname{dist}\left(x_{n_{m}}^{m}, T x_{n_{m}}^{m}\right)=0
$$

and for all $m \geq 1$,

$$
X_{E}\left(\left\{x_{n_{m}}^{m}\right\}\right) \leq \operatorname{dr}\left(E,\left\{x_{n_{m-1}^{m}}^{m-1}\right\}\right)
$$

Consequently,

$$
r\left(E,\left\{x_{n_{m}}^{m}\right\}\right) \leq \lambda r\left(E,\left\{x_{n_{m-1}}^{m-1}\right\}\right) \leq \cdots \leq \lambda^{m} r\left(E,\left\{x_{n_{0}}^{0}\right\}\right)
$$

We show that $\left\{x_{n_{m}}^{m}\right\}_{\mathcal{U}}$ is a Cauchy sequence in $\tilde{X}$. Indeed, for each $m \geq 1$, take an element $\dot{y}_{m} \in \dot{A}^{m-1}$. Then

$$
\left\|\dot{x}_{n_{m}}^{m}-\dot{y}_{m}\right\| \leq\left\|\dot{x}_{n_{m}}^{m}-\left\{x_{n_{m-1}}^{m-1}\right\}_{\mathcal{U}}\right\|+\left\|\left\{x_{n_{m-1}}^{m-1}\right\}_{\mathcal{U}}-\dot{y}_{m}\right\| \leq 2 r\left(E,\left\{x_{n_{m-1}}^{m-1}\right\}\right)
$$


for all $m \geq 1$, and hence

$$
\left\|\left\{x_{n_{m}}^{m}\right\}_{\mathcal{U}}-\left\{x_{n_{m-1}}^{m-1}\right\}_{\mathcal{U}}\right\| \leq\left\|\left\{x_{n_{m}}^{m}\right\}_{\mathcal{U}}-\dot{y}_{m}\right\|+\left\|\dot{y}_{m}-\left\{x_{n_{m-1}}^{m-1}\right\}_{\mathcal{U}}\right\| \leq 3 r\left(E,\left\{x_{n_{m-1}}^{m-1}\right\}\right) .
$$

Thus

$$
\left\|\left\{x_{n_{m}}^{m}\right\}_{\mathcal{U}}-\left\{x_{n_{m-1}}^{m-1}\right\}_{\mathcal{U}}\right\| \leq 3 \lambda^{m-1} r\left(E,\left\{x_{n_{0}}^{0}\right\}\right)
$$

implying that $\left\{x_{n_{m}}^{m}\right\}_{\mathcal{U}}$ is a Cauchy sequence and hence converges to some $\left\{z_{n}\right\}_{\mathcal{U}}$ in $\widetilde{E}$ as $m \rightarrow$ $\infty$. Next, we will show that $\left\{z_{n}\right\}_{\mathcal{U}} \in \dot{E}$. For each $m \geq 0$,

$$
\begin{aligned}
\operatorname{dist}\left(\left\{z_{n}\right\}_{\mathcal{U}}, \dot{E}\right) & \leq\left\|\left\{z_{n}\right\}_{\mathcal{U}}-\left\{x_{n_{m}}^{m}\right\}_{\mathcal{U}}\right\|+\operatorname{dist}\left(\left\{x_{n_{m}}^{m}\right\}_{\mathcal{U}^{\prime}} \dot{E}\right) \\
& \leq\left\|\left\{z_{n}\right\}_{\mathcal{U}}-\left\{x_{n_{m}}^{m}\right\}_{\mathcal{U}}\right\|+\left\|\left\{x_{n_{m}}^{m}\right\}_{\mathcal{U}}-\dot{x}_{1_{m+1}}^{m+1}\right\| \\
& =\left\|\left\{z_{n}\right\}_{\mathcal{U}}-\left\{x_{n_{m}}^{m}\right\}_{\mathcal{U}}\right\|+r\left(E,\left\{x_{n_{m}}^{m}\right\}\right) \\
& \leq\left\|\left\{z_{n}\right\}_{\mathcal{U}}-\left\{x_{n_{m}}^{m}\right\}_{\mathcal{U}}\right\|+\lambda^{m} r\left(E,\left\{x_{n_{0}}^{0}\right\}\right) .
\end{aligned}
$$

Taking $m \rightarrow \infty$ we see that

$$
\operatorname{dist}\left(\left\{z_{n}\right\}_{\mathfrak{u}}, \dot{E}\right)=0
$$

Thus, it follows that there exists $z \in E$ such that $\left\{z_{n}\right\}_{\mathfrak{u}}=\dot{z}$. By Lemma 3.1, $\widetilde{T}$ is continuous at $\dot{z}$, and thus $\widetilde{H}\left(\widetilde{T}\left\{x_{n_{m}}^{m}\right\}_{\mathcal{U}^{\prime}}, \tilde{T} \dot{z}\right) \rightarrow 0$ as $m \rightarrow \infty$. For every $m \geq 0$,

$$
\operatorname{dist}(\dot{z}, \tilde{T} \dot{z}) \leq\left\|\dot{z}-\left\{x_{n_{m}}^{m}\right\}_{\mathcal{U}}\right\|+\operatorname{dist}\left(\left\{x_{n_{m}}^{m}\right\}_{\mathcal{U}^{\prime}}, \widetilde{T}\left\{x_{n_{m}}^{m}\right\}_{\mathcal{U}}\right)+\widetilde{H}\left(\widetilde{T}\left\{x_{n_{m}}^{m}\right\}_{\mathcal{U}^{\prime}}, \widetilde{T} \dot{z}\right)
$$

Taking $m \rightarrow \infty$ we then obtain $\dot{z} \in \widetilde{T} \dot{z}$. By Proposition 2.3, $\widetilde{T} \dot{z}=(\dot{T} z)$, and therefore, $z \in$ $T z$.

Remark 3.4. The proof presented here based on a standard proof appeared in a series of papers $[1,3,5,10]$. However, we cannot follow its proof directly to be able to obtain a result for larger classes of spaces and mappings. We choose an ultralimit approach by using an ultra-asymptotic center $A_{\mathfrak{u}}$ as our main tool. As mentioned earlier, this powerful tool was introduced in [5] by Wiśnicki and Wośko. Thus our proof may not be totally new, but it significantly improves, generalizes, or extends many known results.

(i) Theorem 3.3 (as well as Theorem 3.16) unifies many known theorems in one. Examples of mappings in both theorems are given throughout the rest of the paper.

(ii) Theorem 3.3 improves condition (*) in [8, Definition 3.1] in which the mappings under consideration only are single valued and are self-mappings. Consequently [8, Theorem 3.5] is improved significantly. Obviously, [10, Theorem 1.9] is a special case of Theorem 3.3. 
(iii) In Remark 3.15(ii) below, we show the following implication:

$$
(* *)+(A) \Longrightarrow(*)
$$

Thus results in [18, Corollaries 3.5 and 3.6], [19, Theorems 1 and 2], [20, Theorem 3.3], [9, Theorem 5], [21, Theorem 2.4], [22, Theorem 2], [23, Theorem 4.2, Corollary 4.3, Theorem 4.4], [24, Theorem 2.6], and [25, Theorem 2.3.1] are either improved, generalized, or extended. See Remark 3.17, Corollaries 3.18 and 3.19.

See also Remark 3.24(iii) and (iv).

We now give some examples of mappings satisfying condition $(*)$. We will see that the ultracenter $A_{\mathfrak{U}}\left(E,\left\{x_{n}\right\}\right)$ plays a significant role in verifying condition (2) of condition (*) for a given mapping.

\section{Nonexpansive Mappings}

We will show by following the proof of Theorem 5.3 in [5] that if $T: E \rightarrow K C(X)$ is nonexpansive and $1-x$-contractive such that $T x \subset I_{E}(x)$ for every $x \in E$. Then $T$ satisfies condition $(*)$. The main tools are Lemma 2.5 and the following result.

Theorem 3.5 (see [32, Theorem 11.5]). Let E be a nonempty bounded closed and convex subset of a Banach space $X$ and $F: E \rightarrow K C(X)$ an upper semicontinuous and $X$-condensing mapping. If $F(x) \cap \overline{I_{E}(x)} \neq \emptyset$ for all $x \in E$, then $F$ has a fixed point.

Proposition 3.6. Let $E$ be a nonempty weakly compact convex subset of a Banach space X. Assume that $T: E \rightarrow K C(X)$ is nonexpansive and $1-x$-contractive such that $T x \subset I_{E}(x)$ for every $x \in E$. Then $T$ satisfies condition $(*)$.

Proof. First, we will show that $T$ has an afps in $E$. Let $y_{0} \in E$, and consider, for each $n \geq 1$, the contraction $T_{n}: E \rightarrow K C(X)$ defined by

$$
T_{n}(x)=\frac{1}{n} y_{0}+\left(1-\frac{1}{n}\right) T x, \quad x \in E .
$$

It is not difficult to see that $T_{n}(x) \subset I_{E}(x)$ for every $x \in E$. Since $T$ is $1-x$-contractive, $T_{n}$ is $(1-(1 / n))-x$-contractive, and by Theorem 3.5, there exists a fixed point $x_{n}$ of $T_{n}$. Clearly, $\left\{x_{n}\right\}$ is an afps for $T$ in $E$.

Next, let us see that $T$ has an afps in $A\left(E,\left\{x_{n^{\prime}}\right\}\right)$ for some subsequence $\left\{x_{n^{\prime}}\right\}$ of an afps $\left\{x_{n}\right\}$ for $T$ in $E$. Let $\left\{x_{n}\right\}$ be an afps in $E$. By Proposition 2.1, we can assume that $\left\{x_{n}\right\}$ is weakly convergent and regular relative to $E$. Let $A_{\mathfrak{U}}:=A_{\mathfrak{U}}\left(E,\left\{x_{n}\right\}\right)$. We show that

$$
T x \cap I_{A_{\mathfrak{u}}}(x) \neq \emptyset \quad \text { for every } x \in A_{\mathfrak{u}} .
$$


Let $x \in A_{\mathfrak{U}}$. Observe first that $\left\{x_{n}\right\}_{\mathfrak{U}} \in \tilde{T}\left\{x_{n}\right\}_{\mathcal{U}}$. By Proposition 2.3, $\tilde{T} \dot{x}=(\dot{T} x)$ is compact, and hence there exists $u \in T x$ such that

$$
\left\|\left\{x_{n}\right\}_{\mathcal{U}}-\dot{u}\right\|=\widetilde{H}\left(\widetilde{T}\left\{x_{n}\right\}_{\mathcal{U}}, \tilde{T} \dot{x}\right) \leq\left\|\left\{x_{n}\right\}_{\mathcal{U}}-\dot{x}\right\|=r_{\mathcal{U}}\left(E,\left\{x_{n}\right\}\right)
$$

Since $u \in T x \subset I_{E}(x)$, there exists $\alpha \geq 1$ and $y \in E$ such that $u=x+\alpha(y-x)$. If $\alpha=1$ then $u=y \in E$, and it follows from (3.14) that $u \in A \mathcal{u}$. If $\alpha>1$ then $y=(1 / \alpha) u+(1-1 / \alpha) x$, and therefore, we have

$$
\left\|\left\{x_{n}\right\}_{\mathfrak{U}}-\dot{y}\right\| \leq \frac{1}{\alpha}\left\|\left\{x_{n}\right\}_{\mathfrak{U}}-\dot{u}\right\|+\left(1-\frac{1}{\alpha}\right)\left\|\left\{x_{n}\right\}_{\mathfrak{U}}-\dot{x}\right\| \leq r_{\mathfrak{U}}\left(E,\left\{x_{n}\right\}\right) .
$$

Hence $y \in A_{\mathfrak{u}}$ and consequently $u \in I_{A_{\mathfrak{u}}}(x)$. Thus (3.13) is justified.

Fixed $y_{0} \in A_{\mathcal{U}}$, and consider for each $n \geq 1$, the contraction $T_{n}: A_{\mathfrak{U}} \rightarrow K C(X)$ defined by

$$
T_{n}(x)=\frac{1}{n} y_{0}+\left(1-\frac{1}{n}\right) T x, \quad x \in A_{\mathcal{U}}
$$

As before, $T_{n}$ is $(1-1 / n)-\chi$-contractive, and by Theorem 3.5, there exists a fixed point $z_{n} \in A_{\mathfrak{U}}$ of $T_{n}$. Again, as above, $\left\{z_{n}\right\}$ is an afps for $T$ in $A_{\mathcal{U}}$. By Lemma 2.5, there exists a subsequence $\left\{x_{n^{\prime}}\right\}$ of $\left\{x_{n}\right\}$ such that $\left\{z_{n}\right\} \subset A\left(E,\left\{x_{n^{\prime}}\right\}\right)$.

\section{Diametrically Contractive Mappings}

In [33] Istratescu introduced a new class of mappings.

Definition 3.7 (see [33]). A mapping $T$ defined on a complete metric space $(X, d)$ is said to be diametrically contractive if $\delta(T K)<\delta(K)$ for all closed subsets $K$ with $0<\delta(K)<\infty$. (Here $\delta(K):=\sup \{d(x, y): x, y \in K\}$ denotes the diameter of $K \subset X$.)

$\mathrm{Xu}$ [34] proved the fixed point theorem for a diametrically contractive mapping in the framework of Banach spaces.

Theorem 3.8 (see [34, Theorem 2.3]). Let E be a weakly compact subset of a Banach space X, and let $T: E \rightarrow E$ be a diametrically contractive mapping. Then $T$ has a fixed point.

Dhompongsa and Yingtaweesittikul [35] defined a multivalued version of mappings in Theorem 3.8 which is weaker than the condition required in Definition 3.7. Recall that $T K=$ $\bigcup_{k \in K} T k$ and $E$ is said to be $T$-invariant if $T x \cap E \neq \emptyset$ for all $x \in E$.

Theorem 3.9 (see [35, Theorem 2.2]). Let E be a weakly compact subset of a Banach space X, and let $T: E \rightarrow K C(X)$ be a multivalued mapping such that $\delta(T K \cap K)<\delta(K)$ for all closed sets $K$ with $\delta(K)>0$ and $E$ is invariant under $T$. Then $T$ has a unique fixed point. 
The following result extends Theorem 3.9 partially.

Proposition 3.10. Let $E$ be a nonempty weakly compact convex subset of a Banach space $X$, and let $T: E \rightarrow K C(X)$ be a multivalued mapping such that $\delta(T K) \leq \delta(K)$ for all closed sets $K$ with $\delta(K)>0$ and $E$ is invariant under $T$. Then $T$ satisfies condition $(*)$.

Proof. First, we will see that $T$ has an afps in $E$. Let $y_{0} \in E$, and consider, for each $n \geq 1$, the contraction $T_{n}: E \rightarrow K C(X)$ defined by

$$
T_{n}(x)=\frac{1}{n} y_{0}+\left(1-\frac{1}{n}\right) T x, \quad x \in E .
$$

For $x \in E$, let $a \in T x \cap E$. Thus $(1 / n) y_{0}+(1-1 / n) a \in T_{n} x \cap E$, and therefore, $T_{n} x \cap E \neq \emptyset$ for every $x \in E$. We show that $\delta\left(T_{n} K\right)<\delta(K)$ for all closed sets $K$ with $\delta(K)>0$. Let $K$ be a closed subset of $E$ with $\delta(K)>0$. For $x, y \in T_{n} K$, there exist $x^{\prime}, y^{\prime} \in T K$ such that

$$
\begin{aligned}
& x=\frac{1}{n} y_{0}+\left(1-\frac{1}{n}\right) x^{\prime}, \\
& y=\frac{1}{n} y_{0}+\left(1-\frac{1}{n}\right) y^{\prime},
\end{aligned}
$$

and this entails $\|x-y\|=(1-1 / n)\left\|x^{\prime}-y^{\prime}\right\| \leq(1-1 / n) \delta(T K)$. Hence $\delta\left(T_{n} K\right) \leq(1-1 / n) \delta(T K)<$ $\delta(K)$. By Theorem 3.9, there exists a fixed point $x_{n}$ of $T_{n}$, and thus the sequence $\left\{x_{n}\right\}$ forms an afps for $T$ in $E$.

Next, let us see that $T$ has an afps in $A\left(E,\left\{x_{n^{\prime}}\right\}\right)$ for some subsequence $\left\{x_{n^{\prime}}\right\}$ of an afps $\left\{x_{n}\right\}$ for $T$ in $E$. Let $\left\{x_{n}\right\}$ be an afps in $E$. We can assume that $\left\{x_{n}\right\}$ is weakly convergent and regular relative to $E$. Let $A_{\mathfrak{U}}=A_{\mathcal{U}}\left(E,\left\{x_{n}\right\}\right)$. First, we show that

$$
A_{\mathfrak{u}} \cap T x \neq \emptyset, \quad \text { for every } x \in A_{\mathfrak{u}}
$$

Let $x \in A_{\mathcal{U}}$, and for each $n \geq 1$, we see that $H\left(T x_{n}, T x\right) \leq \delta\left(T\left\{x_{n}, x\right\}\right) \leq \delta\left(\left\{x_{n}, x\right\}\right)=\left\|x_{n}-x\right\|$. Take $y_{n} \in T x_{n}$ so that

$$
\left\|x_{n}-y_{n}\right\|=\operatorname{dist}\left(x_{n}, T x_{n}\right),
$$

and select $z_{n} \in T x$ for each $n$ such that

$$
\left\|z_{n}-y_{n}\right\|=\operatorname{dist}\left(y_{n}, T x\right)
$$

Let $\lim _{n \rightarrow \mathfrak{u}} z_{n}=z \in T x$. Note that

$$
\left\|x_{n}-z\right\| \leq\left\|x_{n}-y_{n}\right\|+\left\|y_{n}-z_{n}\right\|+\left\|z_{n}-z\right\| .
$$


We obtain

$$
\begin{aligned}
\lim _{n \rightarrow \mathcal{U}}\left\|x_{n}-z\right\| & \leq \lim _{n \rightarrow \mathcal{U}}\left\|y_{n}-z_{n}\right\|=\lim _{n \rightarrow \mathcal{U}} \operatorname{dist}\left(y_{n}, T x\right) \leq \lim _{n \rightarrow \mathcal{U}} H\left(T x_{n}, T x\right) \\
& \leq \lim _{n \rightarrow \mathcal{U}}\left\|x_{n}-x\right\|=r_{\mathfrak{U}}\left(E,\left\{x_{n}\right\}\right)
\end{aligned}
$$

proving that $z \in A_{\mathfrak{U}}$. Thus (3.19) is satisfied. Fix $y_{0} \in A_{\mathfrak{U}}$, and consider, for each $n \geq 1$, the contraction $T_{n}: A_{\mathfrak{U}} \rightarrow K C(X)$ defined by

$$
T_{n}(x)=\frac{1}{n} y_{0}+\left(1-\frac{1}{n}\right) T x, \quad x \in A_{\mathfrak{U}}
$$

For $x \in E$, let $a \in A_{\mathcal{U}} \cap T x$. Thus $(1 / n) y_{0}+(1-1 / n) a \in A_{\mathcal{U}} \cap T_{n} x$. Therefore, $A_{\mathfrak{U}} \cap T_{n} x \neq \emptyset$ for every $x \in A_{\mathfrak{U}}$. Let $K$ be a closed subset of $E$ with $\delta(K)>0$. As before, $\delta\left(T_{n} K\right) \leq(1-$ $1 / n) \delta(T K)<\delta(K)$. By Theorem 3.9 (or we can apply Theorem 3.5), there exists a fixed point $z_{n}$ of $T_{n}$. Again, as above, $\left\{z_{n}\right\}$ is an afps for $T$ in $A_{\mathcal{u}}$. Finally, by Lemma 2.5, there exists a subsequence $\left\{x_{n^{\prime}}\right\}$ of $\left\{x_{n}\right\}$ such that $\left\{z_{n}\right\} \subset A\left(E,\left\{x_{n^{\prime}}\right\}\right)$.

\subsection{Kirk-Massa Condition}

In 1990, Kirk and Massa [22] generalized Lim's Theorem [27] using asymptotic centers of sequences and nets and obtained the following result.

Theorem 3.11 (Kirk and Massa theorem). Let $E$ be a nonempty bounded closed and convex subset of a Banach space $X$ and $T: E \rightarrow K C(E)$ a nonexpansive mapping. Suppose that the asymptotic center in $E$ of each bounded sequence of $X$ is nonempty and compact. Then $T$ has a fixed point.

We call the assumption in Kirk and Massa theorem the Kirk-Massa condition. Xu [25] extended Kirk and Massa theorem to nonexpansive nonself-mappings.

Theorem 3.12 ([25, Theorem 2.3.1]). Let X be a Banach space satisfying the Kirk-Massa condition and let $E$ be a nonempty bounded closed and convex subset of $X$. Let $T: E \rightarrow K C(X)$ be a nonexpansive mapping which satisfies the inwardness condition. Then $T$ has a fixed point.

Remark 3.13. Obviously, every space that satisfies the Kirk-Massa condition always has property $\left(D^{\prime}\right)$. Thus, particularly, the fixed point result in Section 3.1 holds for uniform convex Banach spaces, uniformly convex in every direction (UCED) and spaces satisfying the Opial condition.

We aim to extend $\mathrm{Xu}$ 's result to a wider class of mappings. Thus, the domains of mappings are more general than the ones in Section 3.1.

Definition 3.14. Let $\mathcal{U}$ be a free ultrafilter defined on $\mathbb{N}$. Let $E$ be a bounded closed and convex subset of a Banach space X. A mapping $T: E \rightarrow C B(X)$ is said to satisfy condition (**) if it fulfills the following conditions.

(1) $T$ has an afps in $E$;

(2) if $\left\{x_{n}\right\}$ is an apfs for $T$ in $E$ and $x \in E$, then $\lim _{n \rightarrow \mathfrak{u} H} H\left(T x_{n}, T x\right) \leq \lim _{n \rightarrow \mathfrak{u}}\left\|x_{n}-x\right\|$. 
Remark 3.15. (i) Let $E$ be a bounded closed and convex subset of a Banach space $X$, and let a mapping $T: E \rightarrow K C(X)$ satisfy condition $(* *)$. If in addition, $T$ satisfies the following:

(A) every $T$-invariant, closed, and convex subset possesses an afps, then $T$ satisfies condition $(*)$.

Proof. By (1) of condition (**), let $\left\{x_{n}\right\}$ be an apfs for $T$ in E. From Proposition 2.1 by passing through a subsequence, we may assume that $\left\{x_{n}\right\}$ is regular relative to $E$. Let $A_{\mathfrak{U}}=A_{\mathfrak{U}}\left(E,\left\{x_{n}\right\}\right)$ and $x \in A_{\mathcal{U}}$. The compactness of $T x_{n}$ implies that for each $n$ we can take $y_{n} \in T x_{n}$ so that

$$
\left\|x_{n}-y_{n}\right\|=\operatorname{dist}\left(x_{n}, T x_{n}\right)
$$

Since $T x$ is compact, select $z_{n} \in T x$ for each $n$ such that

$$
\left\|z_{n}-y_{n}\right\|=\operatorname{dist}\left(y_{n}, T x\right)
$$

Let $\lim _{n \rightarrow \mathfrak{u}} z_{n}=z \in T x$. Note that

$$
\left\|x_{n}-z\right\| \leq\left\|x_{n}-y_{n}\right\|+\left\|y_{n}-z_{n}\right\|+\left\|z_{n}-z\right\| .
$$

We obtain

$$
\begin{aligned}
\lim _{n \rightarrow \mathcal{U}}\left\|x_{n}-z\right\| & \leq \lim _{n \rightarrow \mathcal{U}}\left\|y_{n}-z_{n}\right\|=\lim _{n \rightarrow \mathcal{U}} \operatorname{dist}\left(y_{n}, T x\right) \leq \lim _{n \rightarrow \mathcal{U}} H\left(T x_{n}, T x\right) \\
& \leq \lim _{n \rightarrow \mathfrak{U}}\left\|x_{n}-x\right\|=r_{\mathfrak{U}}\left(E,\left\{x_{n}\right\}\right)
\end{aligned}
$$

proving that $z \in A_{\mathfrak{U}}$ and hence $A_{\mathfrak{U}} \cap T x \neq \emptyset$ for all $x \in A_{\mathfrak{U}}$, that is, $A_{\mathfrak{U}}$ is $T$-invariant. By assumption, there exists an afps in $A_{\mathfrak{u}}$. By Lemma 2.5, there exists a subsequence $\left\{x_{n^{\prime}}\right\}$ of $\left\{x_{n}\right\}$ such that $\left\{z_{n}\right\} \subset A\left(E,\left\{x_{n^{\prime}}\right\}\right)$. Thus, $T$ satisfies condition $(*)$.

We wonder if we can drop condition (A) in proving the implication: $(* *) \Rightarrow(*)$. An example of a mapping satisfies condition $(*)$ but not condition $(* *)$ is given in Remark 3.24(i).

(ii) In [23, Definition 3.1] the following concept of mappings is defined: a mapping $T: E \rightarrow E$ satisfies condition $(L)$ on $E$ provided that it fulfills the following two conditions.

(1) If a set $D \subset E$ is nonempty, closed, convex, and $T$-invariant, then there exists an afps for $T$ in $D$.

(2) For any afps $\left\{x_{n}\right\}$ of $T$ in $E$ and each $x \in E$,

$$
\underset{n \rightarrow \infty}{\limsup }\left\|x_{n}-T x\right\| \leq \limsup _{n \rightarrow \infty}\left\|x_{n}-x\right\| .
$$

Therefore, (i) shows that the class of mappings satisfying condition $(*)$ contains and extends mappings satisfying condition $(L)$ as a multivalued nonself version. [22].

The main idea of the proof of the following theorem is originated from Kirk and Massa 
Theorem 3.16. Let $X$ be a Banach space satisfying the Kirk-Massa condition, and let $E$ be a nonempty bounded closed and convex subset of X. Let $T: E \rightarrow K C(X)$ be a multivalued mapping satisfying condition (**). If $T$ is an upper semicontinuous mapping, then $T$ has a fixed point.

Proof. Let $\left\{x_{n}\right\}$ be an afps for $T$ in $E$. From Proposition 2.1 by passing through a subsequence, we may assume that $\left\{x_{n}\right\}$ is regular relative to $E$. Let $A_{\mathfrak{U}}=A_{\mathfrak{U}}\left(E,\left\{x_{n}\right\}\right)$. The compactness of $T x_{n}$ implies that for each $n$ we can take $y_{n} \in T x_{n}$ such that

$$
\left\|x_{n}-y_{n}\right\|=\operatorname{dist}\left(x_{n}, T x_{n}\right)
$$

If $x \in A_{\mathcal{U}}$, since $T x$ is compact, select $z_{n} \in T x$ for each $n$ such that

$$
\left\|z_{n}-y_{n}\right\|=\operatorname{dist}\left(y_{n}, T x\right)
$$

Let $\lim _{n \rightarrow u} z_{n}=z \in T x$. Note that

$$
\left\|x_{n}-z\right\| \leq\left\|x_{n}-y_{n}\right\|+\left\|y_{n}-z_{n}\right\|+\left\|z_{n}-z\right\|
$$

Thus

$$
\begin{aligned}
\lim _{n \rightarrow \mathcal{U}}\left\|x_{n}-z\right\| & \leq \lim _{n \rightarrow \mathcal{U}}\left\|y_{n}-z_{n}\right\|=\lim _{n \rightarrow \mathfrak{U}} \operatorname{dist}\left(y_{n}, T x\right) \leq \lim _{n \rightarrow \mathfrak{U}} H\left(T x_{n}, T x\right) \\
& \leq \lim _{n \rightarrow \mathfrak{U}}\left\|x_{n}-x\right\|=r_{\mathfrak{U}}\left(E,\left\{x_{n}\right\}\right)
\end{aligned}
$$

proving that $z \in A_{\mathfrak{U}}$ and hence $A_{\mathfrak{U}} \cap T x \neq \emptyset$ for all $x \in A_{\mathfrak{U}}$. By assumption, $A\left(E,\left\{x_{n}\right\}\right)$ is nonempty and compact which implies that $A_{\mathfrak{U}}$ is also nonempty and compact. Now define a mapping $F: A_{\mathfrak{U}} \rightarrow K C\left(A_{\mathfrak{U}}\right)$ by $F x:=A_{\mathfrak{U}} \cap T x$ for all $x \in A_{\mathfrak{u}}$. Thus $F$ is upper semicontinuous. Indeed, let $\left\{u_{n}\right\} \subset A$ be such that $\lim _{n \rightarrow \infty} u_{n}=u$, and let $v_{n} \in F u_{n}$ be such that $\lim _{n \rightarrow \infty} v_{n}=v$. Since $T$ is upper semicontinuous and $A_{\mathfrak{u}}$ is compact, we have $v \in T u$ and $v \in A_{\mathcal{u}}$, that is $v \in F u$. By the Bohnenblust-Karlin fixed point theorem [36], $F$ and hence $T$, have a fixed point in $A_{\mathfrak{U}}$.

Remark 3.17. If, in addition, mappings in Theorem 3.16 also satisfy condition $(A)$, then the condition on "upper semicontinuity" can be dropped. This is because an afps in a compact set can be chosen so that its asymptotic center is only a singleton, and a fixed point can be easily derived. Consequently, Theorem 3.3 can be extended to a bigger class of domains, namely, the bounded, closed, and convex ones. And the following results are immediate.

Corollary 3.18 (see [23, Theorem 4.2]). Let E be a nonempty compact convex subset of a Banach space $X$ and $T: E \rightarrow E$ a mapping satisfying condition $(L)$. Then, $T$ has a fixed point.

Corollary 3.19 (see [23, Corollary 4.3]). Let E be a nonempty compact convex subset of a Banach space $X$ and $T: E \rightarrow E$ a mapping satisfying condition $(L)$. Suppose that the asymptotic center in $E$ of each sequence in $E$ is nonempty and compact. Then, $T$ has a fixed point.

We give some examples of mappings satisfying condition $(* *)$. The first example is of course the mapping described in Theorem 3.12. 
Condition $\left(C_{\lambda}\right)$. García-Falset et al. [9] introduced the following mappings.

Let $E$ be a nonempty subset of a Banach space $X$. For $\lambda \in(0,1)$, we say that a mapping $T: E \rightarrow X$ satisfies Condition $\left(C_{\curlywedge}\right)$ on $E$ if, for each $x, y \in E$,

$$
\lambda\|x-T x\| \leq\|x-y\| \quad \text { implies }\|T x-T y\| \leq\|x-y\| .
$$

It is natural to define a multivalued version of Condition $\left(C_{\lambda}\right)$ (see [18]).

Let $E$ be a nonempty subset of a Banach space $X$, and let $T: E \rightarrow C B(X)$ be a multivalued mapping. Then $T$ is said to satisfy condition $\left(C_{\lambda}\right)$ for some $\lambda \in(0,1)$ if, for each $x, y \in E$,

$$
\lambda \operatorname{dist}(x, T x) \leq\|x-y\| \quad \text { implies } H(T x, T y) \leq\|x-y\| .
$$

Clearly, $T$ satisfies (2) of condition (**).

Proposition 3.20. Let $E$ be a nonempty bounded closed and convex subset of a Banach space X. If $T: E \rightarrow C B(E)$ satisfies condition $\left(C_{\lambda}\right)$ for some $\lambda \in(0,1)$, then $T$ satisfies condition $(* *)$.

Proof. We only show that $E$ contains an afps for $T$. But this follows from [37, Lemma 2.8].

\section{Generalized Nonexpansive Mappings}

Let $E$ be a nonempty subset of a Banach space $X$. Following [19], a mapping $T: E \rightarrow X$ is a generalized nonexpansive mapping if for some nonnegative constants $\alpha_{1}, \ldots, \alpha_{5}$ with $\sum_{i=1}^{5} \alpha_{i}=1$,

$$
\|T x-T y\| \leq \alpha_{1}\|x-y\|+\alpha_{2}\|x-T x\|+\alpha_{3}\|y-T y\|+\alpha_{4}\|x-T y\|+\alpha_{5}\|y-T x\|,
$$

for each $x, y \in E$.

We will use the following equivalent condition.

For some nonnegative constants $\alpha, \beta$, $\gamma$ with $\alpha+2 \beta+2 \gamma \leq 1$,

$$
\|T x-T y\| \leq \alpha\|x-y\|+\beta(\|x-T x\|+\|y-T y\|)+\gamma(\|x-T y\|+\|y-T x\|)
$$

for all $x, y \in E$.

We introduce a multivalued version of these mappings.

Let $T: E \rightarrow C B(X)$ be a multivalued mapping. $T$ is called a generalized nonexpansive mapping if there exist nonnegative constants $\alpha, \beta, \gamma$ with $\alpha+2 \beta+2 \gamma \leq 1$ such that, for each $x, y \in E$, there holds

$$
H(T x, T y) \leq \alpha\|x-y\|+\beta(\operatorname{dist}(x, T x)+\operatorname{dist}(y, T y))+\gamma(\operatorname{dist}(x, T y)+\operatorname{dist}(y, T x)) .
$$

Proposition 3.21. Let $E$ be a nonempty subset of a Banach space $X$. If $T: E \rightarrow C B(X)$ is a generalized nonexpansive mapping, then $T$ satisfies (2) of condition (**). 
Proof. Let $\left\{x_{n}\right\}$ be an afps for $T$ in $E$ and $x \in E$. By assumption we obtain

$$
\begin{aligned}
H\left(T x_{n}, T x\right) \leq & \alpha\left\|x_{n}-x\right\|+\beta\left(\operatorname{dist}\left(x_{n}, T x_{n}\right)+\operatorname{dist}(x, T x)\right) \\
& +\gamma\left(\operatorname{dist}\left(x_{n}, T x\right)+\operatorname{dist}\left(x, T x_{n}\right)\right) .
\end{aligned}
$$

Since $\operatorname{dist}(x, T x) \leq\left\|x-x_{n}\right\|+\operatorname{dist}\left(x_{n}, T x_{n}\right)+H\left(T x_{n}, T x\right), \operatorname{dist}\left(x_{n}, T x\right) \leq \operatorname{dist}\left(x_{n}, T x_{n}\right)+$ $H\left(T x_{n}, T x\right), \operatorname{dist}\left(x, T x_{n}\right) \leq\left\|x-x_{n}\right\|+\operatorname{dist}\left(x_{n}, T x_{n}\right)$,

$$
\begin{gathered}
\operatorname{dist}(x, T x) \leq \lim _{n \rightarrow \mathcal{U}}\left\|x-x_{n}\right\|+\lim _{n \rightarrow \mathcal{U}} H\left(T x_{n}, T x\right), \\
\lim _{n \rightarrow \mathcal{U}} \operatorname{dist}\left(x_{n}, T x\right) \leq \lim _{n \rightarrow \mathcal{U}} H\left(T x_{n}, T x\right), \\
\lim _{n \rightarrow \mathfrak{U}} \operatorname{dist}\left(x, T x_{n}\right) \leq \lim _{n \rightarrow \mathfrak{U}}\left\|x-x_{n}\right\| .
\end{gathered}
$$

By (3.39),

$$
\begin{aligned}
\lim _{n \rightarrow \mathfrak{U}} H\left(T x_{n}, T x\right) \leq & \alpha \lim _{n \rightarrow \mathfrak{U}}\left\|x_{n}-x\right\|+\beta \lim _{n \rightarrow \mathfrak{U}}\left\|x-x_{n}\right\|+\beta \lim _{n \rightarrow \mathfrak{U}} H\left(T x_{n}, T x\right) \\
& +\gamma \lim _{n \rightarrow \mathfrak{U}} H\left(T x_{n}, T x\right)+\gamma \lim _{n \rightarrow \mathfrak{U}}\left\|x-x_{n}\right\| .
\end{aligned}
$$

Thus

$$
(1-\beta-\gamma) \lim _{n \rightarrow \mathcal{U}} H\left(T x_{n}, T x\right) \leq(\alpha+\beta+\gamma) \lim _{n \rightarrow \mathfrak{U}}\left\|x-x_{n}\right\|
$$

and therefore,

$$
\lim _{n \rightarrow \mathfrak{U}} H\left(T x_{n}, T x\right) \leq \lim _{n \rightarrow \mathfrak{U}}\left\|x_{n}-x\right\|
$$

\section{Takahashi Generalized Nonexpansive Mappings}

Definition 3.22. Let $E$ be a nonempty subset of a Banach space $X$. A mapping $T: E \rightarrow X$ is said to be a Takahashi generalized nonexpansive mapping if, for some $\alpha, \beta \in[0,1]$ with $\alpha+2 \beta \leq 1$, there holds

$$
\|T x-T y\|^{2} \leq \alpha\|x-y\|^{2}+\beta\left(\|y-T x\|^{2}+\|x-T y\|^{2}\right) \quad \text { for } x, y \in E .
$$

The following are examples of Takahashi generalized nonexpansive mappings:

(i) nonexpansive mappings $T$ : $\|T x-T y\| \leq\|x-y\|$;

(ii) nonspreading mappings $T$ [38]: $2\|T x-T y\|^{2} \leq\|y-T x\|^{2}+\|x-T y\|^{2}$; 
(iii) hybrid mappings $T$ [39]: $3\|T x-T y\|^{2} \leq\|y-T x\|^{2}+\|x-T y\|^{2}$;

(iv) mappings $T$ [39]: $2\|T x-T y\|^{2} \leq\|x-y\|^{2}+\|y-T x\|^{2}$;

(v) mappings $T$ : $3\|T x-T y\|^{2} \leq 2\|y-T x\|^{2}+\|x-T y\|^{2}$.

We define a multivalued version of Takahashi generalized nonexpansive mappings and prove that these mappings satisfy (2) of condition $(* *)$.

Proposition 3.23. Let $E$ be a nonempty subset of a Banach space $X$. For nonnegative constants $\alpha, \beta$ with $\alpha+2 \beta \leq 1$, if $T: E \rightarrow K C(X)$ is a multivalued mapping such that

$$
H^{2}(T x, T y) \leq \alpha\|x-y\|^{2}+\beta\left(\operatorname{dist}^{2}(x, T y)+\operatorname{dist}^{2}(y, T x)\right),
$$

then $T$ satisfies (2) of condition (**).

Proof. Let $\left\{x_{n}\right\}$ be an afps for $T$ in $E$ and $x \in E$. By (3.41) and (3.42),

$$
\begin{aligned}
\lim _{n \rightarrow \mathfrak{U}} H^{2}\left(T x_{n}, T x\right) & \leq \alpha \lim _{n \rightarrow \mathcal{U}}\left\|x_{n}-x\right\|^{2}+\beta \lim _{n \rightarrow \mathfrak{U}} \operatorname{dist}^{2}\left(x, T x_{n}\right)+\beta \lim _{n \rightarrow \mathcal{U}} \operatorname{dist}^{2}\left(x_{n}, T x\right) \\
& \leq \alpha \lim _{n \rightarrow \mathfrak{U}}\left\|x_{n}-x\right\|^{2}+\beta \lim _{n \rightarrow \mathfrak{U}}\left\|x_{n}-x\right\|^{2}+\beta \lim _{n \rightarrow \mathfrak{U}} H^{2}\left(T x_{n}, T x\right) .
\end{aligned}
$$

Thus

$$
(1-\beta) \lim _{n \rightarrow \mathcal{U}} H^{2}\left(T x_{n}, T x\right) \leq(\alpha+\beta) \lim _{n \rightarrow \mathfrak{U}}\left\|x-x_{n}\right\|^{2} .
$$

Therefore,

$$
\lim _{n \rightarrow \mathfrak{U}} H\left(T x_{n}, T x\right) \leq \lim _{n \rightarrow \mathfrak{U}}\left\|x_{n}-x\right\|
$$

Remark 3.24. (i) A mapping that satisfies condition $(*)$ need not satisfy condition $(* *)$. Consider a mapping $T:[0,1 / 2] \rightarrow 2^{[0,1 / 2]}$ defined by $T(x)=[\sqrt{x}, \sqrt[3]{x}]$. Since 0 is a fixed point of $T$, the sequence $\left\{x_{n}\right\}$ given by $x_{n} \equiv 0$ for all $n$ forms an afps for $T$. Thus, $T$ fulfills condition (1) of Definition 3.2. If $\left\{x_{n}\right\}$ is an apfs for $T$, then $\left\{x_{n}\right\}$ converges to 0 and $A\left(E,\left\{x_{n}\right\}\right)=\{0\}$. This implies that $A\left(E,\left\{x_{n}\right\}\right)$ has an apfs for $T$, and $T$ satisfies condition (*). On the other hand, for the afps $\left\{x_{n}\right\}$ given by $x_{n} \equiv 0$, if $x \in(0,1 / 2]$, then

$$
\lim _{n \rightarrow \mathcal{U}} H\left(T x_{n}, T x\right)=\sqrt{x}>x=\lim _{n \rightarrow \mathfrak{U}}\left\|x_{n}-x\right\| .
$$

Thus, $T$ fails to satisfy condition $(* *)$.

As mentioned earlier, it is unclear if a mapping, satisfies condition $(* *)$ also satisfies condition $(*)$.

(ii) We do not know if Theorem 3.16 is still valid when " $\lim _{n \rightarrow u}$ " in Definition 3.14 is replaced by "lim sup $\operatorname{su}_{n \rightarrow \infty}$." It is possible that the theorem holds true when the domain $E$ 
is separable. Indeed, by [27, 40] and Kirk [41], we assume the afps $\left\{x_{n}\right\}$ for $T$ to be regular and asymptotically uniform relative to $E$. Thus, $A\left(E,\left\{x_{n^{\prime}}\right\}\right)=A\left(E,\left\{x_{n}\right\}\right)$ for all subsequences $\left\{x_{n^{\prime}}\right\}$ of $\left\{x_{n}\right\}$. Therefore, by Lemma 2.5, it is easy to see that $A_{\mathfrak{U}}=A\left(E,\left\{x_{n}\right\}\right)$. If $x \in A_{\mathfrak{U}}$, then (3.33) becomes

$$
\begin{aligned}
\lim _{n \rightarrow \mathfrak{U}}\left\|x_{n}-z\right\| & \leq \lim _{n \rightarrow \mathfrak{U}}\left\|y_{n}-z_{n}\right\|=\lim _{n \rightarrow \mathfrak{U}} \operatorname{dist}\left(y_{n}, T x\right) \leq \lim _{n \rightarrow \mathfrak{U}} H\left(T x_{n}, T x\right) \\
& \leq \limsup _{n \rightarrow \infty} H\left(T x_{n}, T x\right) \\
& \leq \limsup _{n \rightarrow \infty}\left\|x_{n}-x\right\|=r\left(E,\left\{x_{n}\right\}\right)=r_{\mathfrak{U}}\left(E,\left\{x_{n}\right\}\right) .
\end{aligned}
$$

Hence $A_{\mathfrak{U}} \cap T x \neq \emptyset$, and the rest of the proof follows.

It is observed that if $A_{\mathfrak{U}}=A\left(E,\left\{x_{n}\right\}\right)$ and $A\left(E,\left\{x_{n}\right\}\right)=\{x\}$ is a singleton, then $x$ is automatically a fixed point of $T$. Thus our method provides another proof of Lim [42, Theorem 8], where $X$ is a uniformly convex Banach space, $T$ assumes only compact values and $E$ need not be separable.

(iii) If $T: E \rightarrow E$ is a generalized nonexpansive mapping with any of the following conditions holding, then $T$ satisfies condition (**):

(1) $\alpha+2 \beta+2 \gamma<1$ (see [43, Theorem 4]);

(2) $\alpha+2 \beta+2 \gamma=1$ and $\beta>0, \gamma>0, \alpha \geq 0$ (see [19, Theorem 1]);

(3) $\alpha+2 \beta+2 \gamma=1$ and $\beta>0, \gamma=0, \alpha>0$ (see [44, Theorem 1.1]);

(4) $\alpha+2 \beta+2 \gamma=1$ and $\beta=0, \gamma>0, \alpha \geq 0$ (see [45, Lemma 2.1]).

(iv) Regarding the proof of Theorem 3.16, the fixed point result also holds for weak*nonexpansive mappings (see [46, Definition 1.3]). Thereby [46, Theorem 1.7] is extended to another circumstance.

\section{Acknowledgment}

The authors wish to thank the National Research University Project under Thailand's Office of the Higher Education Commission for financial support.

\section{References}

[1] T. Domínguez Benavides and P. Lorenzo Ramírez, "Fixed-point theorems for multivalued nonexpansive mappings without uniform convexity," Abstract and Applied Analysis, vol. 2003, no. 6, pp. 375-386, 2003.

[2] T. Domínguez Benavides and P. Lorenzo Ramírez, "Fixed point theorems for multivalued nonexpansive mappings satisfying inwardness conditions," Journal of Mathematical Analysis and Applications, vol. 291, no. 1, pp. 100-108, 2004.

[3] T. Domínguez Benavides and P. Lorenzo Ramírez, "Asymptotic centers and fixed points for multivalued nonexpansive mappings," Annales Universitatis Mariae Curie-Skłodowska. Sectio A, vol. 58, pp. 37-45, 2004.

[4] S. Dhompongsa, A. Kaewcharoen, and A. Kaewkhao, "The Domínguez-Lorenzo condition and multivalued nonexpansive mappings," Nonlinear Analysis: Theory, Methods \& Applications, vol. 64, no. 5, pp. 958-970, 2006. 
[5] A. Wiśnicki and J. Wośko, "Banach ultrapowers and multivalued nonexpansive mappings," Journal of Mathematical Analysis and Applications, vol. 326, no. 2, pp. 845-857, 2007.

[6] B. Garvira, Some moduli in Banach spaces with applications in metric fixed point theory, Ph.D. thesis, Universidad de Sevilla, Sevilla, Spain, 2006.

[7] S. Dhompongsa, T. Domínguez Benavides, A. Kaewcharoen, A. Kaewkhao, and B. Panyanak, "The Jordan-von Neumann constants and fixed points for multivalued nonexpansive mappings," Journal of Mathematical Analysis and Applications, vol. 320, no. 2, pp. 916-927, 2006.

[8] T. Butsan, S. Dhompongsa, and W. Takahashi, "A fixed point theorem for pointwise eventually nonexpansive mappings in nearly uniformly convex Banach spaces," Nonlinear Analysis: Theory, Methods E Applications, vol. 74, no. 5, pp. 1694-1701, 2011.

[9] J. García-Falset, E. Llorens-Fuster, and T. Suzuki, "Fixed point theory for a class of generalized nonexpansive mappings," Journal of Mathematical Analysis and Applications, vol. 375, no. 1, pp. 185195, 2011.

[10] S. Dhompongsa and W. Inthakon, "Note on the (DL)-condition and the separability of Banach spaces," in Proceedings of the 6th International Conference on Nonlinear Analysis and Convex Analysis, pp. 37-51, Tokyo, Japan, 2009.

[11] T. Domínguez Benavides and B. Gavira, "The fixed point property for multivalued nonexpansive mappings," Journal of Mathematical Analysis and Applications, vol. 328, no. 2, pp. 1471-1483, 2007.

[12] T. Domínguez Benavides and B. Gavira, "Does Kirk's theorem hold for multivalued nonexpansive mappings?" Fixed Point Theory and Applications, vol. 2010, Article ID 546761, 20 pages, 2010.

[13] B. Gavira, "Some geometric conditions which imply the fixed point property for multivalued nonexpansive mappings," Journal of Mathematical Analysis and Applications, vol. 339, no. 1, pp. 680690, 2008.

[14] A. Kaewkhao, "The James constant, the Jordan-von Neumann constant, weak orthogonality, and fixed points for multivalued mappings," Journal of Mathematical Analysis and Applications, vol. 333, no. 2, pp. 950-958, 2007.

[15] S. Saejung, "Remarks on sufficient conditions for fixed points of multivalued nonexpansive mappings," Nonlinear Analysis: Theory, Methods E Applications, vol. 67, no. 5, pp. 1649-1653, 2007.

[16] J. Zhang and Y. Cui, "On some geometric constants and the fixed point property for multivalued nonexpansive mappings," Fixed Point Theory and Applications, vol. 2010, Article ID 596952, 12 pages, 2010.

[17] T. Kuczumow and S. Prus, "Compact asymptotic centers and fixed points of multivalued nonexpansive mappings," Houston Journal of Mathematics, vol. 16, no. 4, pp. 465-468, 1990.

[18] A. Abkar and M. Eslamian, "Fixed point theorems for Suzuki generalized nonexpansive multivalued mappings in Banach spaces," Fixed Point Theory and Applications, vol. 2010, Article ID 457935, 10 pages, 2010.

[19] J. Bogin, "A generalization of a fixed point theorem of Goebel, Kirk and Shimi," Canadian Mathematical Bulletin, vol. 19, no. 1, pp. 7-12, 1976.

[20] S. Dhompongsa, W. Inthakon, and A. Kaewkhao, “Edelstein's method and fixed point theorems for some generalized nonexpansive mappings," Journal of Mathematical Analysis and Applications, vol. 350, no. 1, pp. 12-17, 2009.

[21] M. R. Haddadi, H. Mazaheri, and M. H. Labbaf Ghasemi, "Relation between fixed point and asymptotical center of nonexpansive maps," Fixed Point Theory and Applications, vol. 2011, Article ID 175989, 6 pages, 2011.

[22] W. A. Kirk and S. Massa, "Remarks on asymptotic and Chebyshev centers," Houston Journal of Mathematics, vol. 16, no. 3, pp. 357-364, 1990.

[23] E. Llorens Fuster and E. Moreno Gálvez, "The fixed point theory for some generalized nonexpansive mappings," Abstract and Applied Analysis, vol. 2011, Article ID 435686, 15 pages, 2011.

[24] T. Suzuki, "Fixed point theorems and convergence theorems for some generalized nonexpansive mappings," Journal of Mathematical Analysis and Applications, vol. 340, no. 2, pp. 1088-1095, 2008.

[25] H.-K. Xu, "Metric fixed point theory for multivalued mappings," Dissertationes Mathematicae, vol. 389, p. 39, 2000.

[26] K. Goebel and W. A. Kirk, Topics in Metric Fixed Point Theory, vol. 28 of Cambridge Studies in Advanced Mathematics, Cambridge University Press, Cambridge, UK, 1990.

[27] T. C. Lim, "A fixed point theorem for multivalued nonexpansive mappings in a uniformly convex Banach space," Bulletin of the American Mathematical Society, vol. 80, pp. 1123-1126, 1974.

[28] A. G. Aksoy and M. A. Khamsi, Nonstandard Methods in Fixed Point Theory, Universitext, Springer, New York, NY, USA, 1990. 
[29] M. A. Khamsi and B. Sims, "Ultra-methods in metric fixed point theory," in Handbook of Metric Fixed Point Theory, W. A. Kirk and B. Sims, Eds., pp. 177-199, Kluwer Academic Publishers, Dordrecht, The Netherlands, 2001.

[30] B. Sims, "Ultra"-Techniques in Banach Space Theory, vol. 60 of Queen's Papers in Pure and Applied Mathematics, Queen's University, Kingston, Canada, 1982.

[31] S. Dhompongsa, W. A. Kirk, and B. Panyanak, "Nonexpansive set-valued mappings in metric and Banach spaces," Journal of Nonlinear and Convex Analysis, vol. 8, no. 1, pp. 35-45, 2007.

[32] K. Deimling, "Fixed points of weakly inward multis," Nonlinear Analysis: Theory, Methods $\mathcal{E}$ Applications, vol. 10, no. 11, pp. 1261-1262, 1986.

[33] V. I. Istrăţescu, "Some fixed point theorems for convex contraction mappings and mappings with convex diminishing diameters. I," Annali di Matematica Pura ed Applicata, vol. 130, pp. 89-104, 1982.

[34] H.-K. Xu, "Diametrically contractive mappings," Bulletin of the Australian Mathematical Society, vol. 70, no. 3, pp. 463-468, 2004.

[35] S. Dhompongsa and H. Yingtaweesittikul, "Diametrically contractive multivalued mappings," Fixed Point Theory and Applications, vol. 2007, Article ID 19745, 7 pages, 2007.

[36] H. F. Bohnenblust and S. Karlin, "On a theorem of Ville," in Contributions to the Theory of Games, H. W. Kuhn and A. W. Tucker, Eds., Annals of Mathematics Studies, no. 24, pp. 155-160, Princeton University Press, Princeton, NJ, USA, 1950.

[37] A. Khaewcharoen and B. Panyanak, "Fixed point theorems for some generalized multivalued nonexpansive mappings," in Proceedings of the 4th Conference on Fixed Point Theory and Applications, pp. 30-31, Bangkok, Thailand, 2010.

[38] F. Kohsaka and W. Takahashi, "Fixed point theorems for a class of nonlinear mappings related to maximal monotone operators in Banach spaces," Archiv der Mathematik, vol. 91, no. 2, pp. 166-177, 2008.

[39] W. Takahashi, "Fixed point theorems for new nonlinear mappings in a Hilbert space," Journal of Nonlinear and Convex Analysis, vol. 11, no. 1, pp. 79-88, 2010.

[40] K. Goebel, "On a fixed point theorem for multivalued nonexpansive mappings," Annales Universitatis Mariae Curie-Skłodowska. Sectio A, vol. 29, pp. 69-72, 1975.

[41] W. A. Kirk, "Nonexpansive mappings in product spaces, set-valued mappings and $k$-uniform rotundity," in Nonlinear Functional Analysis and Its Applications, Part 2 (Berkeley, Calif., 1983), F. Browder, Ed., vol. 45 of Proc. Sympos. Pure Math., pp. 51-64, American Mathematical Society, Providence, RI, USA, 1986.

[42] T. C. Lim, "On asymptotic centers and fixed points of nonexpansive mappings," Canadian Journal of Mathematics, vol. 32, no. 2, pp. 421-430, 1980.

[43] B. E. Rhoades, "A comparison of various definitions of contractive mappings," Transactions of the American Mathematical Society, vol. 226, pp. 257-290, 1977.

[44] M. Greguš, Jr., "A fixed point theorem in Banach space," Bollettino dell'Unione Matematica Italiana, vol. 17, no. 1, pp. 193-198, 1980.

[45] J. S. Bae, "Fixed point theorems of generalized nonexpansive maps," Journal of the Korean Mathematical Society, vol. 21, no. 2, pp. 233-248, 1984.

[46] M. Abbas and B. E. Rhoades, "Fixed point theorems for two new classes of multivalued mappings," Applied Mathematics Letters, vol. 22, no. 9, pp. 1364-1368, 2009. 


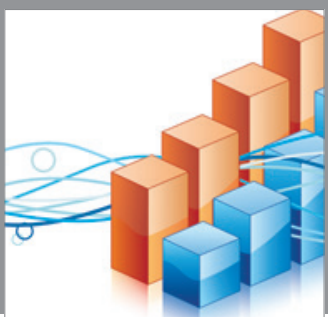

Advances in

Operations Research

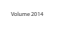

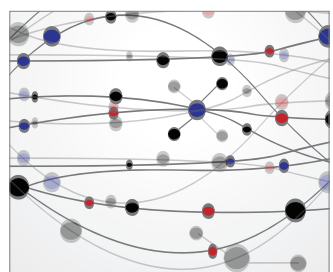

\section{The Scientific} World Journal
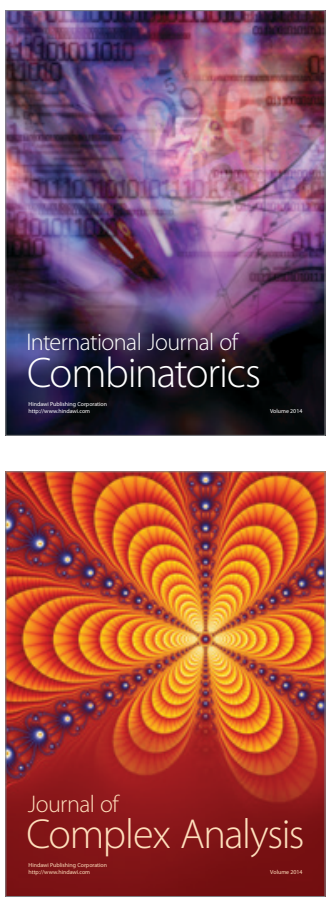

International Journal of

Mathematics and

Mathematical

Sciences
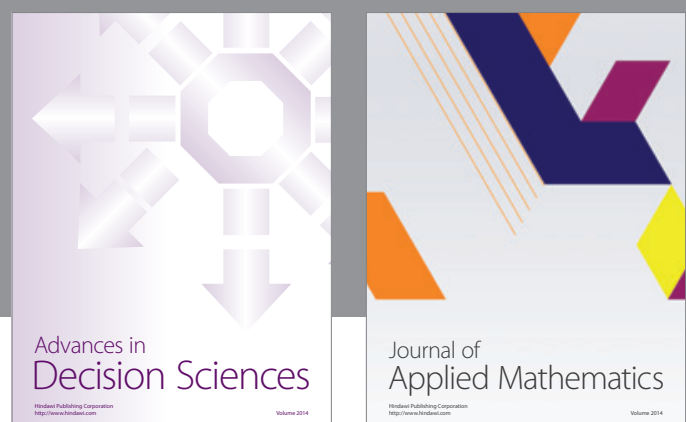

Journal of

Applied Mathematics
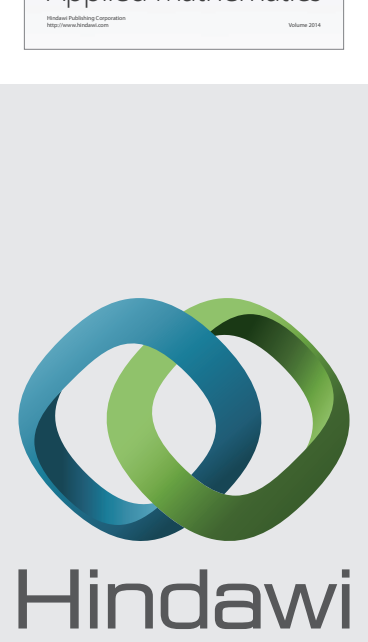

Submit your manuscripts at http://www.hindawi.com
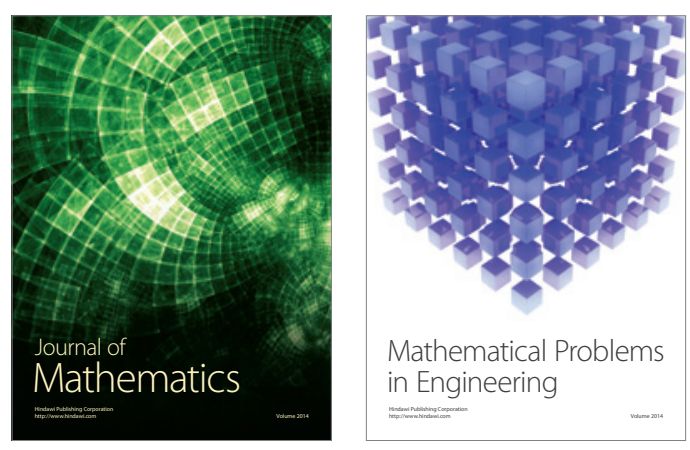

Mathematical Problems in Engineering
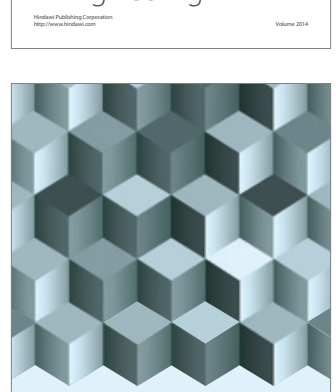

Journal of

Function Spaces
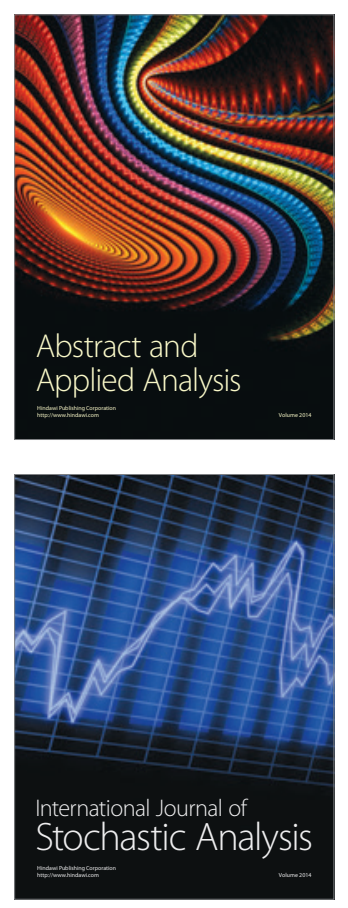

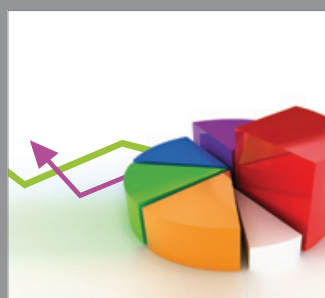

ournal of

Probability and Statistics

Promensencen
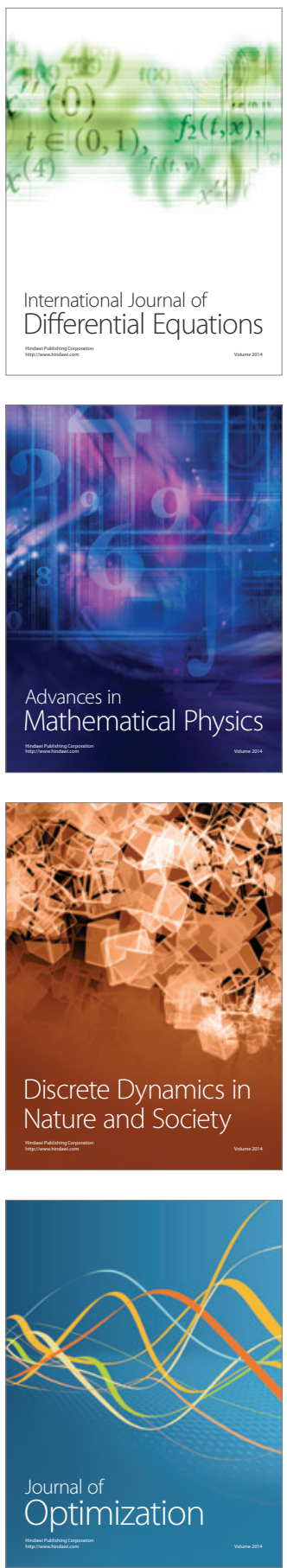